\title{
MAJOR CLINICAL RISK FACTORS FOR FEBRILE SEIZURES IN CHILDREN AGED SIX TO SIXTY MONTHS.
}

\author{
1. MBBS, FCPS (Paediatric Medicine) \\ Senior Registrar Paeds Medicine \\ The Children's Hospital and \\ The Institute of Child Health, Multan. \\ 2. FCPS (Paediatric Medicine) \\ Consultant Paediatrition \\ Tehsil Headquarter Hospital, Rojhan. \\ 3. MBBS, FCPS (Peads) \\ PGR Paediatric Medicine \\ The Children's Hospital and \\ The Institute of Child Health, Multan.
}

Correspondence Address: Dr. Shahid Ishaq

Department of Paeds Medicine The Children's Hospital and the Institute of Child Health, Multan. fazal171@gmail.com

Article received on: 09/03/2019 Accepted for publication: 24/07/2019

\section{Shahid Ishaq ${ }^{1}$, Ejaz Mazari², Fazal ur Rehman ${ }^{3}$}

ABSTRACT... Objectives: Febrile seizures (FS) are the most common type of seizures and typically transpire in children with ages from 6 to 60 months. This study was planned to find out major clinical risk factors for seizures in febrile children who were aged 6 to 60 months. A total of 100 febrile children aged 6 to 60. Study Design: Analytical Study. Setting: Department of Neurology, Children's Hospital and the Institute of Child Health, Multan. Period: From $1^{\text {st }}$ April 2018 to $31^{\text {st }}$ December 2018. Material \& Methods: Group A had 40 children with febrile seizures while group $B$ had 60 febrile children but without seizures. Demographic features along with family history of $(\mathrm{H} / \mathrm{O})$ epilepsy as well as family history of febrile seizure, types of seizure and infection diseases were noted and analyzed using SPSS version 20 . Odds ratio was calculated for various risk factors. Chi square test was applied and $\mathrm{P}$ value $<0.05$ was considered as significant. Results: Out of a total of 100 children, there were 54 (54.0\%) male and $46(46.0 \%)$ female. There was no statistical difference in terms of gender between the two groups ( $p$ value $=0.566$ ). Overall, mean age of the children was 26.02 months with standard deviation of 13.4 months. There were $28(70.0 \%)$ children who reported with simple seizures while complex seizures were found in 12 (30.0\%) cases. Statistically significant difference (p value $=0.001$ ) was seen in terms of types of infections between the two study groups. When risk of seizures for various risk factors was calculated, family $\mathrm{H} / \mathrm{O} \mathrm{FS}$, family $\mathrm{H} / \mathrm{O}$ epilepsy, and upper RTI were as 14, 7 and 3 times respectively and turned out to be the major risk factors for seizures in febrile children. Conclusions: Family H/O FS, family H/O epilepsy and upper RTIs are the major risk factors related with seizures in febrile children. Measures to prevent these risk factors can decrease the burden of FS in our population.

Key words: $\quad$ Epilepsy, Family History, Risk Factor, Seizures.

Article Citation: Ishaq S, Mazari E, Fazal ur Rehman. Major clinical risk factors for febrile seizures in children aged six to sixty months. Professional Med J 2020; 27(5):891-894. DOI: 10.29309/TPMJ/2020.27.05.3397

\section{INTRODUCTION}

Seizures are known as one of the most frequent reasons for children's visit to pediatric emergencies. ${ }^{1}$ FS is noted as the commonest kind of seizures involving around $5 \%$ of children who are 6 to 60 months of age. ${ }^{1,2} \mathrm{FS}$ are described as seizures happening after the age of 1 month, accompanied with fever, without any infections to the CNS, no association with past neonatal or unprovoked seizures, and those children who do not meet the criteria for other acute symptomatic seizures. Most common age involving FS is 6 to 60 months while the mean onset is said to be around 18 months. Incidence of FS falls in between 3 to $8 \%$ in children who are younger than 60 months. ${ }^{1-3}$
Genetics and environmental factors are involved in the pathogenesis of FS. Some studies have stated age $<60$ months, family $\mathrm{H} / \mathrm{O} F S$, family $\mathrm{H} / \mathrm{O}$ epilepsy as possible risk factors for FS. ${ }^{4-6}$ Prenatal issues like asphyxia, complications related to parturition and premature birth are also said to be related with $\mathrm{FS}^{7-9}$ Over the years, literature has mentioned that majority of the children continue with normal health and growth after $\mathrm{FS}^{3,4}$ In the recent years, it has been noted that children who have FS, may go on to have recurrent FS or are more prone to developing epilepsy. ${ }^{3-5}$ This study was conducted to find out major clinical risk factors for seizures in febrile children who were aged 6 to 60 months. 


\section{MATERIAL \& METHODS}

A total of 100 febrile children aged 6 to 60 months were enrolled for this descriptive-analytical study, conducted at the department of neurology, Children's Hospital and the Institute of Child Health, Multan from $1^{\text {st }}$ April 2018 to $31^{\text {st }}$ December 2018. This study was approved by institute's ethical committee. Verbal consent was taken from parents/guardians of the children and data was put on a predesigned proforma. Patients were divided into 2 groups: Group A had 40 children with febrile seizures while group $B$ had 60 febrile children but without seizures. FS was labeled according to the clinical symptoms. Children with meningitis, encephalitis, or with any sort of brain hemorrhage, neurodevelopmental hindrance, those with febrile status epilepticus, and who had any trauma in the past were not included in this study. Demographic features along with family $\mathrm{H} / \mathrm{O}$ epilepsy as well as family $\mathrm{H} / \mathrm{O}$ febrile seizure, types of seizure and common infection diseases were noted and analyzed using SPSS version 20. Frequency and percentage were calculated for qualitative variables like gender, family history, type of FS, and various infections like upper respiratory tract infection, urinary tract infections and pneumonia. Mean and standard deviation (SD) were calculated for age and weight of the children. Odds ratio was calculated for various risk factors. Chi square test was applied and $P$ value $<0.05$ was considered as significant.

\section{RESULTS}

Out of a total of 100 children, there were 54 (54.0\%) male and 46 (46.0\%) female. In Group-A, there were $23(57.5 \%)$ male and $17(42.5 \%)$ female while in Group B there were 31 (51.7\%) male and $29(48.3 \%)$ female. There was no statistical difference in terms of gender between the two groups (P-Value $=0.566$ ). Overall, mean age of the children was 26.02 months with standard deviation of 13.4 months. In Group A, mean age was 25.18 months with standard deviation of 12.5 months whereas in Group B, mean age was 26.6 months with standard deviation of 14.0 months $(p$ value $=0.796)$.

There were 28 (70.0\%) children who reported with simple seizures while complex seizures were found in $12(30.0 \%)$ cases.

Mean weight of the children in Group A was 10.57 $+2.68 \mathrm{~kg}$ in comparison to $10.20+2.42 \mathrm{~kg}$ in Group B ( $p$ value $=0.328)$.

In Group A, family history of FS was found 13 (32.5\%) children in comparison to $2(3.3 \%)$ in children in Group B (P-Value < 0.001). In Group A, 15 (37.5\%) children had a family history of epilepsy while in Group B 5 (8.3\%) had epilepsy in family history ( $p$ value $<0.001$ ). In Group A, $26(65.0 \%)$ children were delivered with cesarean section in comparison to 30 (50.0\%) in Group B $(P$-Value $=0.139)$.

Statistically significant difference (P-Value = 0.001 ) was seen in terms of types of infections between the two study groups.

When risk of seizures for various risk factors was calculated, family $\mathrm{H} / \mathrm{O}$ FS, family $\mathrm{H} / \mathrm{O}$ epilepsy, upper RTIs and cesarean section were as 14, 7, 3 and times respectively and turned out to be the major risk factors for seizures in febrile children.

\begin{tabular}{|l|c|c|c|}
\hline \multicolumn{1}{|c|}{ Risk Factors } & OR & $\mathbf{9 5 \%}$ Cl & P-Value \\
\hline Family History of FS & 13.96 & $2.94-66.26$ & $<0.001$ \\
\hline $\begin{array}{l}\text { Family History of } \\
\text { Epilepsy }\end{array}$ & 6.60 & $2.16-20.17$ & $<0.001$ \\
\hline Cesarean Section & 1.86 & $0.81-4.23$ & 0.139 \\
\hline Upper RTI & 3.04 & $1.31-7.07$ & 0.009 \\
\hline
\end{tabular}

Table-I. Risk factors for seizures in febrile children with or without seizures.

\section{DISCUSSION}

Overall, mean age of the children was 26.02 months with standard deviation of 13.4 months. In Group A, mean age was 25.18 months with standard deviation of 12.5 months whereas in Group B, mean age was 26.6 months with standard deviation of 14.0 months ( $p$ value $=0.796)$. In terms of mean age, our results were quite consistent with other studies who found similar mean age in children with febrile seizures. ${ }^{10-13}$

We found 28 (70.0\%) children having simple 
seizures while complex seizures were found in $12(30.0 \%)$ cases. A local study conducted by Hussain $\mathrm{S}$ and colleagues in 2015 and a recent study from Iran found similar results where $78 \%$ and $75.3 \%$ of children respectively were having simple seizures. ${ }^{14,15}$ Simple FS have been documented as the most frequent type. It is defined as generalized clinical features, duration $<15$ minutes and one episode of seizure in 24 hours. Complex FS have focal clinical manifestation with a duration spanning $>15$ minutes while $>1$ episode in 24 hours. ${ }^{3}$ Children with FS should be evaluated to rule out any underlying CNS etiology. It has been advised that lumbar puncture needs to be done in infants who are $<12$ months of age with prolonged complex FS or febrile status epile pticus, as well as those who have $\mathrm{H} / \mathrm{O}$ partial antibiotic treatments. In children with simple FS, routine EEG as well as neuroimaging are not advised. ${ }^{3}$

We found that $32.5 \%$ of the children with FS had a positive family $\mathrm{H} / \mathrm{O}$ FS while $37.5 \%$ were having family $\mathrm{H} / \mathrm{O}$ epilepsy. About $25-40 \%$ of children with FS have a positive family history of $\mathrm{FS}^{3}$ In a recent study from Iran, it was noted that $25 \%$ of the children with seizures had a family history positive for FS whereas $17.5 \%$ were having positive family $\mathrm{H} / \mathrm{O}$ epilepsy. ${ }^{14}$

There are many causes of seizures in children and it is also known that many other conditions mimic seizures that make it difficult for the timely identification and evaluation for the clinicians.

In the current study, statistically significant difference (P-Value $=0.001$ ) was seen in terms of types of infections between the two study groups. When risk of seizures for various risk factors was calculated, family H/O FS 14 times, family history of epilepsy as 7 times, cesarean section 2 times, upper RTI 3 times were turned out to be the major risk factors for seizures.

FS has a good prognosis in majority of the children but we should keep in mind that the risk for development of epilepsy in the presence of family history of FS as well as family history of epilepsy may project as high as $10 \%$. All the efforts should be made for early identification of the risk factors and preventing children from these risk factors could prove to be the best option in febrile children.

\section{CONCLUSION}

Family $\mathrm{H} / \mathrm{O}$ FS, family $\mathrm{H} / \mathrm{O}$ epilepsy and upper RTIs are the major risk factors related with seizures in febrile children. Measures to prevent these risk factors can decrease the burden of FS in our population.

\section{Copyright@ 24 July, 2019.}

\section{REFERENCE}

1. Heydarian F, Ashrafzadeh F, Kam S. Simple febrile seizure: The role of serum sodium levels in prediction of seizure recurrence during the first $\mathbf{2 4}$ hours. Iran J Child Neurol. 2009; 3(2):31-4.

2. Fetveit A. Assessment of febrile seizures in children. Eur J Pediatr. 2008; 167(1):17-27.

3. Reet Sidhu, Kohilavani velayudam and gregory barnes. Pediatric seizures. Pediatrics in Review 2013; $34 ; 333-41$.

4. Abd Ellatif F, El Garawany H. Risk factors of febrile seizures among preschool children in Alexandria. $J$ Egypt Public Health Assoc. 2002; 77(1-2):159-72.

5. Mahyar A, Ayazi P, Fallahi M, Javadi A. Risk factors of the first febrile seizures in Iranian children. Int $\mathrm{J}$ Pediatr. 2010; 2010:862897.

6. Veisani Y, Delpisheh A, Sayehmiri K. Familial history and recurrence of febrile seizures; $A$ systematic review and meta-analysis. Iran J Pediatr. 2013; 23(4):389-95.

7. Nakayama J. Progress in searching for the febrile seizure susceptibility genes. Brain Dev. 2009; 31(5):359-65.

8. Abuekteish F, Daoud AS, al-Sheyyab M, Nou'man M. Demographic characteristics and risk factors of first febrile seizures: A Jordanian experience. Trop Doct. 2000; 30(1):25-7.

9. Seinfeld DS, Pellock JM. Recent research on febrile seizures: A review. J Neurol Neurophysiol. 2013; 4(165). doi: 10.4172/2155-9562.1000165.

10. Gourabi HE, Bidabadi E, Cheraghalipour F, Aarabi Y, Salamat F. Febrile seizures. Demo graphic features and causative factors. Iran J Child Neurol. 2012; 6: 337. 
11. Rabbani MW, Ali I, Latif HZ, Basit A, Rabbani MA. Serum zinc level in children presenting with febrile seizures. Pak J Med Sci. 2013; 29:1008-11.

12. Rehman N, Billoo AG. Association between iron deficiency anemia and febrile seizures. J Coll Physicians Surg Pak. 2005; 15:338-40.

13. Heydarian $F$, Vatankhah $H$. The role of anemia in first simple febrile seizure in children aged 6 months to 5 years old. Neurosciences. 2012; 17:226-9.
14. Heydarian F, Bakhtiari E, Yousefi S, Heidarian M. The first febrile seizure: An updated study for clinical risk factors. Iran J Pediatr. 2018 December; 28(6):e69761.

15. Hussain S, Tarar SH, Sabir M. Febrile seizures: Demographic, clinical and etiological profile of children admitted with febrile seizures in a tertiary care hospital. J Pak Med Assoc. 2015; 65(9):1008-10.

\begin{tabular}{|c|c|c|c|}
\hline \multicolumn{3}{|c}{ AUTHORSHIP AND CONTRIBUTION DECLARATION } \\
\hline Sr. \# & Author(s) Full Name & \multicolumn{1}{|c|}{ Contribution to the paper } & Author(s) Signature \\
\hline 1 & Shahid Ishaq & Methodology, Literature review. & \\
\hline 2 & Ejaz Mazari & $\begin{array}{l}\text { Methodology, Literature review, } \\
\text { Data analysis. } \\
\text { Data collection, Data analysis, } \\
\text { Drafting. }\end{array}$ \\
\hline 3 & Fazal ur Rehman & \\
\hline
\end{tabular}

